\title{
Original Contributions
}

Z Gerontol Geriat 2021 · 54:768-774 https://doi.org/10.1007/s00391-021-01908-5 Received: 27 January 2021

Accepted: 26 April 2021

Published online: 11 June 2021

(c) The Author(s) 2021

Ulrich Lindemann ${ }^{1}$ Sebastian Krumpoch ${ }^{2}$ - Clemens Becker ${ }^{1}$ Cornel C. Sieber ${ }^{2,3}$. Ellen Freiberger ${ }^{2}$

' Department of Clinical Gerontology and Rehabilitation, Robert-Bosch-Hospital, Stuttgart, Germany ${ }^{2}$ Institute for Biomedicine of Aging (IBA), Friedrich-Alexander-University of Erlangen-Nürnberg (FAU), Nuremberg, Germany

${ }^{3}$ Department of Internal Medicine, Kantonsspital Winterthur, Winterthur, Switzerland

\section{The course of gait speed during a $400 \mathrm{~m}$ walk test of mobility limitations in community- dwelling older adults}

\section{Introduction}

Long-distance walk tests, when performed as fast as possible, are widely used to assess cardiorespiratory fitness. In contrast, the $400-\mathrm{m}$ walk test (400MWT) with the instruction to walk with usual pace is often incorporated into epidemiological studies to measure mobility limitations [1-3]. Compared to other functional outcome measures such as the short physical performance battery (SPPB), it is less prone to ceiling effects in high-functioning older adults [4] and mean usual gait speed can be calculated from completion time.

Habitual/usual gait speed is increasingly recognized as a vital sign [5]. Gait speed slower than $1.0 \mathrm{~m} / \mathrm{s}$ has been predictive of negative outcomes, like frailty, mortality, mobility limitations, falls and decreased quality of life [6-8]. Therefore, shortdistance walk tests over $4 \mathrm{~m}$, $8 \mathrm{~m}$ or $10 \mathrm{~m}$, when performed at usual pace, are commonly used to describe a person's general physical ability $[9,10]$. Assessment protocols covering several research questions can be overdemanding and should be merged whenever possible. Intuitively, the assessment of a shortdistance walk to assess gait speed and a long-distance walk could be combined if both tests are performed with the same pace instructions. Measurements of usual walking have been shown to be affected by various factors (e.g. distance, acceleration/deceleration phase, instructions, measurement instruments), which should therefore be standardized [5]. For instance, Najafi et al. (2009) found a significant increase in stride time velocity during long walking distances (e.g. >20m) compared to short walking distances (e.g. $<10 \mathrm{~m}$ ) in older persons [11]. The course of gait speed during even longer distances has not been investigated so far. It is therefore questionable whether 400MWT generally show plateau phases (e.g. start, middle, end) that would allow integration of a shortdistance walk test.

In addition, a person's walking performance is modified by individual characteristics [12], such as physical, psychological and/or general health aspects. Accordingly, the performance of functionally limited persons during a $400 \mathrm{MWT}$ should be more affected by factors like fatigue, stability/regularity of walking [12, 13], executive function, fear of falling $[14,15]$, comorbidity and falls history. In contrast, healthy older adults should be more influenced by motivational factors resulting in overperforming or initial/final sprint.

The aim of this study was to describe the course of gait speed during a 400MWT of usual walking pace in community-dwelling older adults and to determine whether a possible plateau phase of gait speed would allow integration of a shortdistance walk test. In 
Table 1 Descriptive parameters, which partly served as covariates ( $\left({ }^{(}\right)$, of all $(n=148)$ participating older adults

\begin{tabular}{|c|c|}
\hline Descriptive parameters/covariates $^{a}$ & Mean \pm SD (range) or $n(\%)$ \\
\hline Sex, female/male ${ }^{a}$ & $90(60.8) / 58(39.2)$ \\
\hline Age (years) & $80.4 \pm 4.4(71-93)$ \\
\hline Body height (cm) & $164.0 \pm 10.4(142-198)$ \\
\hline Body weight (kg) & $75.0 \pm 16.3(43.9-121.9)$ \\
\hline Body mass index $\left(\mathrm{kg} / \mathrm{m}^{2}\right)$ & $27.8 \pm 4.9(17.6-43.3)$ \\
\hline Short physical performance battery $(0-12)$ & $11.0 \pm 1.6(4-12)$ \\
\hline Functional comorbidity index $(0-18)^{\mathrm{a}}$ & $3.6 \pm 2.2(0-9)$ \\
\hline Fallers, yes $/ \mathrm{no}^{\mathrm{a}}$ & $55(37.2) / 93(62.8)$ \\
\hline Falls efficacy scale - international $(16-64)^{a}$ & $21.1 \pm 5.7(16-44)$ \\
\hline Geriatric depression scale $(0-15)$ & $1.69 \pm 2.0(0-10)$ \\
\hline Montreal cognitive assessment $(0-30)$ & $25.4 \pm 2.9(13-30)$ \\
\hline Trail making test delta $(s)^{a}$ & $86.2 \pm 51.7(12-266)$ \\
\hline $400 \mathrm{~m}$ walking aid, yes/no & $19(12.8) / 129(87.2)$ \\
\hline 400-m completion, yes/no & $144(97.3) / 4(2.7)$ \\
\hline $400-m$ rest, yes/no & $9(6.1) / 139(93.9)$ \\
\hline 8-m gait speed (m/s) & $1.21 \pm 0.3(0.33-1.80)$ \\
\hline 400-m gait speed $(\mathrm{m} / \mathrm{s})$ & $1.14 \pm 0.3(0.26-1.74)$ \\
\hline 8-m stride length variability (\%) ${ }^{\mathrm{a}}$ & $2.97 \pm 1.5(0.8-8.6)$ \\
\hline 8-m step width variability (\%) ${ }^{\mathrm{a}}$ & $27.05 \pm 14.2(7.1-78.2)$ \\
\hline
\end{tabular}

Table 2 Mean gait speed during the $400 \mathrm{~m}$ walk test for all subgroups

\section{Covariates \\ (Dichotomized variables)}

Gender, female/male

Step width variability, $\leq 27 \% />27 \% a$

Stride length variability, $\leq 2.86 \% />2.86 \%^{b}$

Falls, yes/no

Functional comorbidity index, $\leq 3 />3$

Falls efficacy scale - international,

$\leq 22 />22^{c}$

Trail making test delta, $<72 \mathrm{~s} / \geq 72 \mathrm{~s}^{d}$

a Ciprandi et al. (2017) [24]

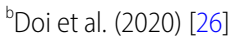

'Delbaere et al. (2010) [25]

${ }^{\mathrm{d}}$ Hobert et al. (2011) [27]

\section{N Gait speed [m/s],} Mean (95\% confidence interval)

90/58 $1.11(1.11-1.12) / 1.19(1.18-1.20)$

96/52 $1.12(1.11-1.13) / 1.18(1.18-1.19)$

$83 / 651.22(1.21-1.22) / 1.05(1.04-1.06)$

$55 / 93 \quad 1.10(1.09-1.11) / 1.17(1.16-1.18)$

75/73 $1.24(1.23-1.24) / 1.04(1.03-1.06)$

$109 / 391.21(1.20-1.22) / 0.94(0.93-0.95)$

73/74 $1.18(1.17-1.18) / 1.11(1.10-1.12)$

addition, we investigated the impact of physical, psychological, and general health-related covariates on the course of gait speed during a 400MWT.

\section{Material and methods}

\section{Subjects and design}

In total 148 community-dwelling older adults from the greater area of a southeast German city were assessed between May and December 2019. The participants were recruited via an existing data tee of the Friedrich Alexander University (43_19B) and all participants gave written informed consent.

\section{Primary outcome}

The 400MWT was performed according to an evaluated protocol to assess mobility limitations [2]. This test consisted of 10 laps over a $20 \mathrm{~m}$ course marked by two traffic cones, placed $18.5 \mathrm{~m}$ apart, as an average turning distance of $1.5 \mathrm{~m}$ was assumed (shown in - Fig. 1). Participants started from a standing position at the left cone and walked up and down the corridor in a continuous loop, passing the course twice in each lap. The objective was to complete the $400 \mathrm{~m}$ at a usual, preferably steady, pace but without overexertion. The instruction was as follows: "This is not a fitness test. Please walk at a speed as if you were taking a stroll in the park, knowing that you have a longer distance to cover." To increase ecological validity, participants were asked to wear their own habitual outdoor shoes and use their assistive devices. Only wheeled walkers, which probably would have caused problems during the turning phases of the $400 \mathrm{~m}$ walk test, were not permitted. Participants paused to rest whenever necessary and the number of rests, taken while standing without touching the walls, was recorded. The test was aborted at any time if requested or at signs of overexertion. Total time of the 400MWT and each individual lap were assessed by stopwatch and mean gait speed was calculated. In the case of noncompletion, gait speed was obtained from the distance and time walked until drop-out.

pool and distribution of flyers. Inclusion criteria were an age of at least 70 years, living independently, the ability to walk $400 \mathrm{~m}$ and the ability to follow instructions. Participants were excluded if they were dependent on the use of wheeled walkers and/or reported serious orthopedic and/or neurologic diseases causing gait impairments. Assessments lasted approximately 120-240 min and consisted of a structured personal interview and a gait analysis, including a 400MWT, in a well-lit hallway. The study protocol was approved by the ethics commit-

\section{Descriptive parameters/covariates}

Demographic and anthropometric data, such as age, sex, body weight and height were recorded. With respect to psychological parameters, depressive symptoms were assessed using the 15-item geriatric depression scale (GDS) [16]. The scores ranged from 0 to 15 , with greater values indicating greater depressive symptoms. The Montreal cognitive assessment (MoCA) measured global cognitive function with a maximum/best score of 30 
[17]. Previous studies have demonstrated a relationship between psychological outcomes, such as executive function, and gait abilities of older adults [15]. Therefore, executive function was measured by the trail making test (TMT) [18] consisting of a part A (visuomotor tracking) and a part B (visuoconceptual function). The difference between the two completion times (TMT delta) was taken as outcome. The falls efficacy scale-international (FES-I), a 16-item questionnaire with a maximum/worst score of 64 [19] was performed. Fear of falling is prevalent among older adults, affects gait performance and is a proven predictor of fall risk [14].

Regarding general health, comorbidity was evaluated using the functional comorbidity index (FCI), a list of 18 comorbid diseases that are associated with physical function [20]. Additionally, history of falling was obtained, with "fallers" defined as individuals who reported at least one fall during the last year.

In terms of physical parameters, global physical function of the participants was described using the SPPB, which included a repeated sit-to-stand transfer, a static balance test and a $4 \mathrm{~m}$ usual paced walk test [21]. Each test component of the SPBB had a possible score of $0-4$. Total scores ranged from 0 to 12 , with higher values indicating better physical function. Furthermore, gait speed, stride length variability and step width variability, indicating capacity and quality/regularity of walking [12], of all participants were assessed on an $8 \mathrm{~m}$ long instrumented walkway with embedded pressure sensors (GAITRite, Franklin, NJ, USA) with additional $2.5 \mathrm{~m}$ for acceleration and deceleration before and behind the mat $[22,23]$. Gait variability quantifies fluctuations in temporal and spatial walking patterns and is an indirect measure of gait stability and regularity $[24,13,12]$. Following a standardized protocol, participants were instructed to walk with their usual pace and their own outdoor shoes.

Assessment instruments showing floor or ceiling effects were not considered as covariates for subgroup analyses (shown in - Tables 1 and 2). Furthermore, age was also excluded due to its

Z Gerontol Geriat 2021 · 54:768-774 https://doi.org/10.1007/s00391-021-01908-5

(c) The Author(s) 2021

\section{U. Lindemann · S. Krumpoch · C. Becker · C. C. Sieber · E. Freiberger}

\section{The course of gait speed during a $400 \mathrm{~m}$ walk test of mobility limitations in community-dwelling older adults}

\section{Abstract}

Background. The 400-m walk test (400MWT) of usual gait speed is an assessment of mobility limitations in geriatric medicine and sarcopenic research.

Objective. The aim of this study was to describe the course of gait speed during a 400MWT in community-dwelling older adults in terms of physical, psychological and general health-related outcomes. Possible plateau phases during the $400 \mathrm{MWT}$ could enable integrated measurements of short distance walk tests.

Methods. In this study 148 community-dwelling older adults (mean age $80.4 \pm 4.4$ years, $61 \%$ women) performed a $400 \mathrm{MWT}$ at comfortable gait speed. Additionally, an $8 \mathrm{~m}$ walk test was carried out and history of falling, sex, comorbidities, fear of falling, executive function and gait variability were determined as covariates.
Results. Gait speed was higher in the beginning and the end of the 400MWT compared to the middle part with respect to all analyzed covariates. Mean gait speed of the $8 \mathrm{~m}$ walk test was significantly faster than mean gait speed of the 400MWT ( $t$ $(\mathrm{df}=147)=0.07, p=0.001)$.

Conclusion. The course of gait speed during a 400MWT performed by communitydwelling older adults was not affected by sex, gait variability, comorbidity, history of falling, fear of falling or executive function. Gait speed measurements of the 400MWT do not fully represent assessment of supervised short distance gait speed in communitydwelling adults.

\section{Keywords}

Cross-sectional studies - Geriatric assessment . Humans - Walking · Aging

\section{Der Verlauf der Ganggeschwindigkeit in einem 400 m-Gehtest zur Untersuchung von Mobilitätseinschränkungen bei selbstständig lebenden älteren Erwachsenen}

\section{Zusammenfassung}

Hintergrund. Der 400 m-Gehtest (400MWT) in habitueller Ganggeschwindigkeit erfasst Mobilitätseinschränkungen in der Geriatrie und Sarkopenieforschung.

Ziel. Ziel der Studie war es, den Verlauf der Ganggeschwindigkeit während eines 400MWT bei selbstständig lebenden älteren Erwachsenen in Abhängigkeit von physischen, psychologischen und allgemein gesundheitsbezogenen Faktoren zu beschreiben. Mögliche Plateauphasen während des 400MWT könnten integrierte Messungen kurzer Gehtests ermöglichen. Methode. Insgesamt 148 selbstständig lebende ältere Erwachsene (Durchschnittsalter $80,4 \pm 4,4$ Jahre, $61 \%$ Frauen) absolvierten einen 400MWT in habitueller Ganggeschwindigkeit. Zusätzlich wurde ein $8 \mathrm{~m}$-Gehtest durchgeführt, daneben wurden die Parameter Sturzereignisse, Geschlecht Komorbidität, Angst vor Stürzen, exekutive Funktionen und Gangvariabilität als Kovariaten bestimmt.
Ergebnisse. Die Ganggeschwindigkeit im 400MWT war hinsichtlich aller analysierten Kovariaten anfangs und am Ende höher als im mittleren Teil. Die durchschnittliche Ganggeschwindigkeit im $8 \mathrm{~m}$-Gehtest war signifikant höher als im 400MWT ( $t$ $(\mathrm{df}=147)=0,07, p=0,001)$.

Schlussfolgerung. Der Verlauf der Ganggeschwindigkeit während eines 400MWT bei selbstständig lebenden älteren Erwachsenen wurde nicht von den Kovariaten Geschlecht, Gangvariabilität, Komorbidität, Sturzereignisse, Sturzangst oder exekutive Funktionen beeinflusst. Ganggeschwindigkeitsmessungen des 400MWT sind nur bedingt auf supervidierte, kürzere Assessments der Ganggeschwindigkeit bei selbstständig lebenden Erwachsenen generalisierbar.

Schlüsselwörter

Querschnittsstudien · Geriatrisches Assessment · Menschen · Gehen · Altern 


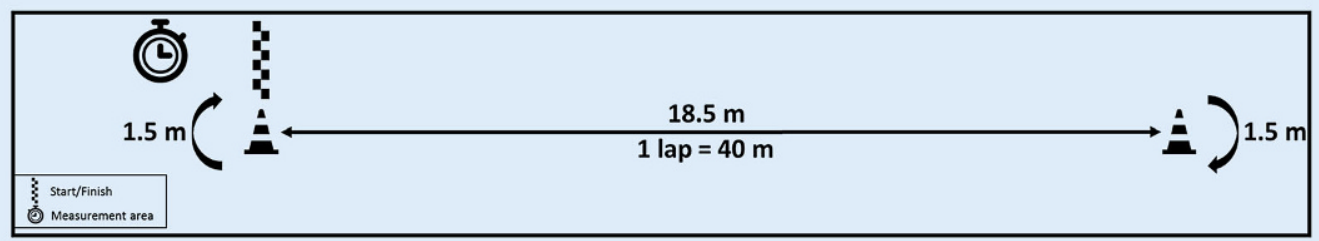

Fig. $1<$ Start/finish at the left cone
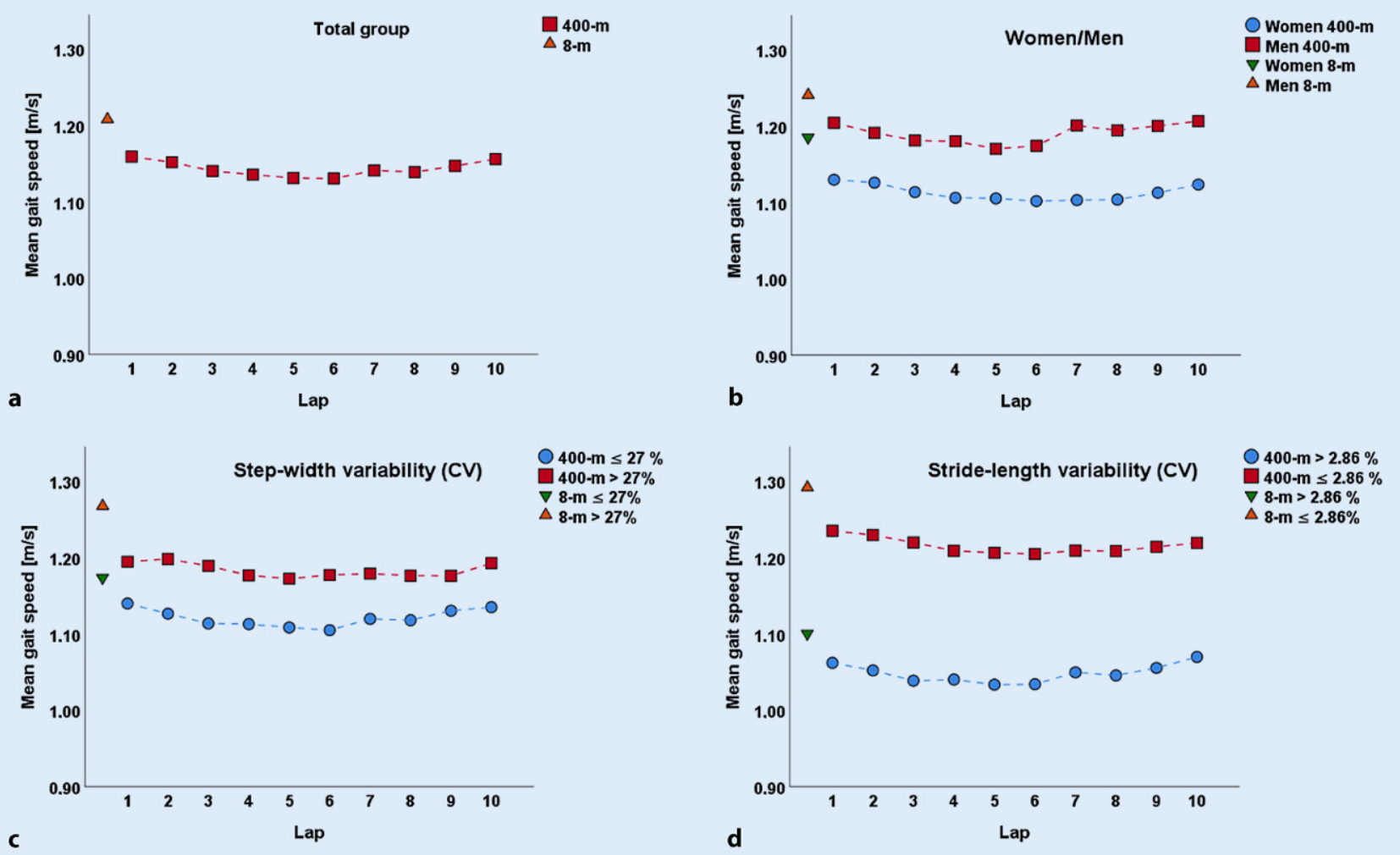

Fig. $2 \Delta$ Gait speed during the $400 \mathrm{~m}$ walk test and $8 \mathrm{~m}$ walk test for (a) the total group, and the covariates (b) women and men, cstep width variability ${ }^{a} \leq 27 \%$ and $>27 \%$ and d stride length variability ${ }^{b} \leq 2.86 \%$ and $>2.86 \% .{ }^{a, b}$ Assessed with GAITRite system

narrow range and high association with the other covariates.

\section{Statistics}

Variables were described by mean, standard deviation and 95\% confidence interval, minimum and maximum. For subgroup analysis the results of covariates were dichotomized to high versus low performers regarding reference values [24-27], median split (comorbidity) or obvious categories (sex, falls). A paired $\mathrm{t}$-test was performed to analyze the difference between the gait speed of the 400MWT and gait speed of the $8 \mathrm{~m}$ walk test. All analyses were performed using
SPSS $^{\circledR}$ version 24.0 (SPSS, Inc., Chicago, IL, USA).

\section{Results}

In this study 148 participants with a mean age of 80 years $(61 \%$ women) were recruited of whom 144 (97\%) completed the 400MWT and 19 (13\%) walked with a walking aid. The SPPB (81 participants with maximum score), the GDS (90 participants with minimum score) and the MoCA (79 participants with a score of $>25$ ) showed ceiling effects and were therefore not considered for subgroup analysis (meaning dichotomization as high and low performers). Descriptive parameters of all participants are presented in detail in - Table 1. The mean gait speed of all dichotomized variables over all 10 laps of the $400 \mathrm{MWT}$ is described in - Table 2. Differences in gait speed between low and high performers were shown, as confidence intervals did not overlap for any covariate analyzed. A general pattern of gait speed during the 400MWT was observed that was similar between men and women and for all other subgroups (shown in • Fig. 2 and 3 ). Gait speed peaked in the first lap, then dropped to a relatively stable plateau phase in the middle part of the $400 \mathrm{~m}$ and increased again through the end of the test. Furthermore, mean gait 

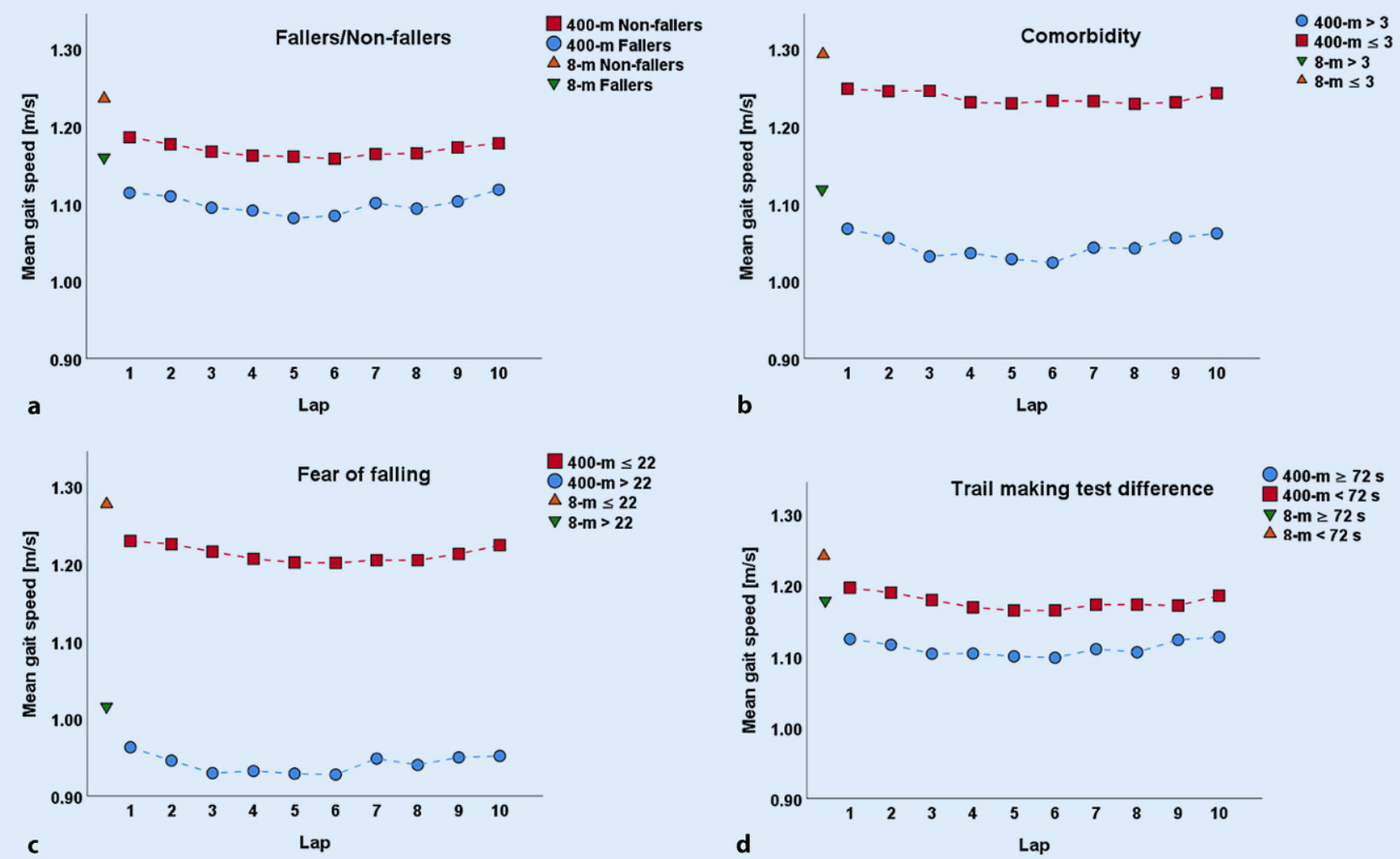

400-m $\leq 22$ 400-m>22 $\Delta-m \leq 22$
$\nabla 8-m>22$

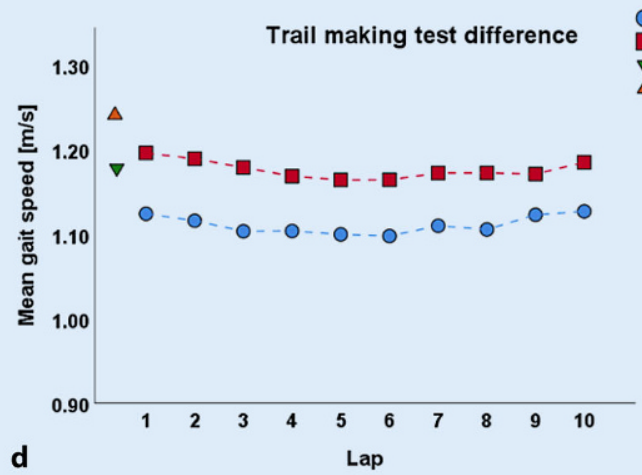

Fig. $3 \Delta$ Gait speed during the $400 \mathrm{~m}$ walk test and $8 \mathrm{~m}$ walk test for the covariates a fallers and non-fallers, $\mathbf{b}$ comorbidity $\leq 3$ and $>3$, c fear of falling $\leq 22$ and $>22$ and $\mathbf{d}$ trail making test difference $<72 \mathrm{~s}$ and $\geq 72 \mathrm{~s}$

speed of the $8 \mathrm{~m}$ walk test was significantly faster than mean gait speed of the 400MWT $(t(\mathrm{df}=147)=0.07, p=0.001)$.

\section{Discussion}

Our results present a general pattern of gait speed during a 400MWT in a relatively fit population of communitydwelling older adults who are unaffected by physical, psychological, and general health-related outcomes. In detail, this course of gait speed was shown to be independent of the influence of the covariates sex, gait variability, fear of falling, executive function, comorbidity or falls history. A relatively stable plateau phase of gait speed was observed in the midsection of the 400MWT. With respect to steady state gait speed measurements, our results imply that a shortdistance walk test of usual gait speed could be included into this middle part of the $400 \mathrm{~m}$; however, since a paired t-test showed a significant difference between the walking speeds of the $400 \mathrm{MWT}$ and an $8 \mathrm{~m}$ walk test, this recommendation can only be issued with reservations.

It is noteworthy that the gait speed in each lap of the 400MWT was slower than in the shortdistance walk test. This could be explained by fatigue and/or several decelerations during the turning phases around the cones. Furthermore, walking over a longer distance may reduce the awareness of being observed. It has been shown that supervised gait speed measurements in a laboratory were faster than unsupervised gait speed assessed during daily life in community-dwelling adults [28]. This suggestion is corroborated by the fact that gait speed decreased after the start over 2-3 laps in our study. Future studies should therefore compare gait speed of the middle part of a 400MWT with daily life unsupervised gait speed.

Our results contrast with the abovementioned publication of Najafi et al. [11], which examined only a small sample $(n=24)$ of older adults. It could be argued that their long walks $(20 \mathrm{~m})$ were much shorter than the 400MWT and thus were not longdistance walks. Furthermore, our results are corroborated by Pasma et al. who found that gait speed of a $10 \mathrm{~m}$ walk was faster than velocities measured during a 6-min walk, although the persons were instructed to walk as fast as possible during this longdistance walk [29]. Nevertheless, our results cannot be applied to longdistance walk tests, such as the 2-min, 6-min [30], 12-min [31] or the 400MWT [32], if instructed to walk as far or as fast as possible over the given time or distance in order to assess cardiorespiratory fitness. Here, a different course of gait speed could be possible. As a limitation of our study a participation of mainly physical healthy older adults has occurred due to the broad inclusion criteria affecting the generalizability of the study.

\section{Conclusion}

In conclusion, the general pattern of decrease, plateau and increase of gait speed 
during a $400 \mathrm{MWT}$ is similar for high and low performers. Furthermore, the course of gait speed during a long-distance walk tests performed by community-dwelling older adults in usual pace is not modified by sex, gait variability, comorbidity, history of falling, fear of falling or executive function. Since the awareness of being observed is probably higher at the beginning and the end of long-distance measurements, the middle part of the 400MWT might correspond to unsupervised gait speed during daily life in community-dwelling older adults. Future studies should investigate this.

\section{Relevance to clinical practice}

- The course of gait speed during a 400MWT performed by community-dwelling older adults is not modified by sex, regularity of walking, comorbidity, history of falling, fear of falling or executive function.

- Mean gait speed of an $8 \mathrm{~m}$ shortdistance walk test was significantly faster than mean gait speed of the 400MWT.

\section{Corresponding address}

\section{Sebastian Krumpoch}

Institute for Biomedicine of Aging (IBA), Friedrich-Alexander-University of ErlangenNürnberg (FAU)

Nuremberg, Germany

sebastian.krumpoch@fau.de

Acknowledgements. This paper is submitted in partial fulfilment of the requirements for obtaining the degree Dr. rer. biol. hum. (PhD in human biology) for the secondary author.

Funding. This research did not receive any specific grant from funding agencies in the public, commercial, or not-for-profit sectors.

Author Contribution. All authors contributed to the study conception and design. Data collection and analysis were performed by Sebastian Krumpoch. The first draft of the manuscript was written by Ulrich Lindemann and Sebastian Krumpoch and all authors commented on previous versions of the manuscript. All authors read and approved the final manuscript.

Funding. Open Access funding enabled and organized by Projekt DEAL.

\section{Declarations}

Conflict of interest. U. Lindemann, S. Krumpoch, C. Becker, C.C. Sieber and E. Freiberger declare that they have no competing interests.

The study was performed in accordance with the ethical standards of the ethics committee of the local university and with the 1964 Helsinki declaration and its later amendments. This article does not contain any studies with animals performed by any of the authors. This study was approved by the Friedrich-AlexanderUniversity ethics committee (43_19B). All participants of this project gave written informed consent for data analysis and publication.

Open Access. This article is licensed under a Creative Commons Attribution 4.0 International License, which permits use, sharing, adaptation, distribution and reproduction in any medium or format, as long as you give appropriate credit to the original author(s) and the source, provide a link to the Creative Commons licence, and indicate if changes were made. The images or other third party material in this article are included in the article's Creative Commons licence, unless indicated otherwise in a credit line to the material. If material is not included in the article's Creative Commons licence and your intended use is not permitted by statutory regulation or exceeds the permitted use, you will need to obtain permission directly from the copyright holder. To view a copy of this licence, visit http://creativecommons.org/licenses/by/4.0/.

\section{References}

1. Chang M, Cohen-Mansfield J, Ferrucci L, Leveille S, Volpato S, de Rekeneire N et al (2004) Incidence of loss of ability to walk 400 meters in a functionally limited older population. J Am Geriatr Soc 52(12):2094-2098

2. Rolland YM, Cesari M, Miller ME, Penninx BW, Atkinson HH, Pahor M (2004) Reliability of the 400-m usual-pace walk test as an assessment of mobility limitation in older adults. J Am Geriatr Soc 52(6):972-976

3. Vestergaard S, Patel KV, Walkup MP, Pahor M, Marsh AP, Espeland MA et al (2009) Stopping to rest during a 400-meter walk and incident mobility disability in older persons with functional limitations. J Am Geriatr Soc 57(2):260-265

4. Sayers SP, Guralnik JM, Newman AB, Brach JS, Fielding RA (2006) Concordance and discordance between two measures of lower extremity function: 400 meter self-paced walk and SPPB. Aging Clin Exp Res 18(2):100-106

5. Middleton A, Fritz SL, Lusardi M (2015) Walking speed: the functional vital sign. J Aging Phys Act 23(2):314-322

6. Abellan van Kan G, Rolland Y, Andrieu S, Bauer J, Beauchet O, Bonnefoy M et al (2009) Gait speed at usual pace as a predictor of adverse outcomes in community-dwelling older people an International Academy on Nutrition and Aging (IANA) Task Force. J Nutr Health Aging 13(10):881-889

7. Panel on Prevention of Falls in Older Persons, American Geriatrics Society and British Geriatrics Society (2011) Summary of the Updated American Geriatrics Society/British Geriatrics Society clinica practice guideline for prevention of falls in older persons. J Am Geriatr Soc 59(1):148-157
8. Studenski S, Perera S, Patel K, Rosano C, Faulkner K, Inzitari M et al (2011) Gait speed and survival in older adults. JAMA 305(1):50-58

9. Graham JE, Ostir GV, Fisher SR, Ottenbacher KJ (2008) Assessing walking speed in clinical research: a systematic review. J Eval Clin Pract 14(4):552-562

10. Kim H-J, Park I, Lee HJ, Lee O (2016) The reliability and validity of gait speed with different walking pace and distances against general health, physical function, and chronic disease in aged adults. JExerc Nutr Biochem 20(3):46-50

11. Najafi B, Helbostad JL, Moe-Nilssen R, Zijlstra W, Aminian K (2009) Does walking strategy in older people change as a function of walking distance? Gait Posture 29(2):261-266

12. Lindemann U (2020) Spatiotemporal gait analysis of older persons in clinical practice and research: Which parameters are relevant? Z Gerontol Geriatr 53(2):171-178

13. Montero-Odasso $M$, Almeida QJ, Bherer $L$, Burhan AM, Camicioli R, Doyon J et al (2019) Consensus on shared measures of mobility and cognition: from the Canadian Consortium on Neurodegeneration in Aging (CCNA). J Gerontol A Biol Sci Med Sci 74(6):897-909

14. Makino K, Makizako H, Doi T, Tsutsumimoto K, Hotta R, Nakakubo S et al (2017) Fear of falling and gait parameters in older adults with and without fall history. Geriatr Gerontol Int 17(12):2455-2459

15. Yogev G, Hausdorff JM, Giladi N (2009) The role of executive function and attention in gait. Mov Disord 23(3):329-342

16. Yesavage JA, Brink TL, Rose TL, Lum O, Huang V, Adey $M$ et al (1982) Development and validation of a geriatric depression screening scale: a preliminary report. J Psychiatr Res 17(1):37-49

17. Nasreddine ZS, Phillips NA, Bédirian V, Charbonneau S, Whitehead V, Collin I et al (2005) The Montreal Cognitive Assessment, MoCA: a brief screening tool for mild cognitive impairment. JAm Geriatr Soc 53(4):695-699

18. Reitan RM (1992) Trail making test: manual for administration and scoring. Reitan Neuropsychology Laboratory, Tucson

19. Yardley L, Beyer N, Hauer K, Kempen G, PiotZiegler C, Todd C (2005) Development and initial validation of the Falls Efficacy Scale-International (FES-I). Age Ageing 34(6):614-619

20. Groll DL, To T, Bombardier C, Wright JG (2005) The development of a comorbidity index with physical function as the outcome. J Clin Epidemiol 58(6):595-602

21. Guralnik JM, Simonsick EM, Ferrucci L, Glynn RJ, Berkman LF, Blazer DG et al (1994) A short physical performance battery assessing lower extremity function: association with self-reported disability and prediction of mortality and nursing home admission. J Gerontol 49(2):M85-M94

22. Lindemann U, Najafi B, Zijlstra W, Hauer K, Muche R, Becker C et al (2008) Distance to achieve steady state walking speed in frail elderly persons. Gait Posture 27(1):91-96

23. Macfarlane PA, Looney MA (2008) Walkway length determination for steady state walking in young and older adults. Res Q Exerc Sport 79(2):261-267

24. Ciprandi D, Bertozzi F, Zago M, Ferreira CLP, Boari G, Sforza C et al (2017) Study of the association between gait variability and physical activity. Eur Rev Aging Phys Act 14:19

25. Delbaere K, Close JCT, Mikolaizak AS, Sachdev PS, Brodaty H, Lord SR (2010) The Falls Efficacy Scale International (FES-I). A comprehensive longitudinal validation study. Age Ageing 39(2):210-216 
26. Doi T, Nakakubo S, Tsutsumimoto K, Kim M-J, Kurita S, Ishii H et al (2020) Spatio-temporal gait variables predicted incident disability. JNeuroEngineering Rehabil 17(1):11

27. Hobert MA, Niebler R, Meyer SI, Brockmann K Becker C, Huber $\mathrm{H}$ et al (2011) Poor trail making test performance is directly associated with altered dual task prioritization in the elderly-baseline results from the TREND study. Plos One 6(11):e27831

28. Van Ancum JM, van Schooten KS, Jonkman NH, Huijben B, van Lummel RC, Meskers CGM et al (2019) Gait speed assessed by a 4-m walk test is not representative of daily-life gait speed in community-dwelling adults. Maturitas 121:28-34

29. Pasma JH, Stijntjes M, Ou SS, Blauw GJ, Meskers CGM, Maier AB (2014) Walking speed in elderly outpatients depends on the assessment method. Age 36(6):9736

30. Guyatt GH, Thompson PJ, Berman LB, Sullivan MJ, Townsend M, Jones NL et al (1985) How should we measure function in patients with chronic heart and lung disease? JChronic Dis 38(6):517-524

31. Butland RJ, Pang J, Gross ER, Woodcock AA, Geddes DM (1982) Two-, six-, and 12-minute walking tests in respiratory disease. Br Med J Clin Res 284(6329):1607-1608

32. Simonsick EM, Fan E, Fleg JL (2006) Estimating cardiorespiratory fitness in well-functioning older adults: treadmill validation of the long distance corridor walk. J Am Geriatr Soc 54(1):127-132

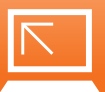

\section{Dem Geheimnis des EKGs auf der Spur: 108 Fälle im Intensivkurs EKG}

Bei einem 73-jährigen Patienten bestehen Schwindel und Dyspnoe unter Belastung. Dieses EKG liegt Ihnen zur Befundung vor.

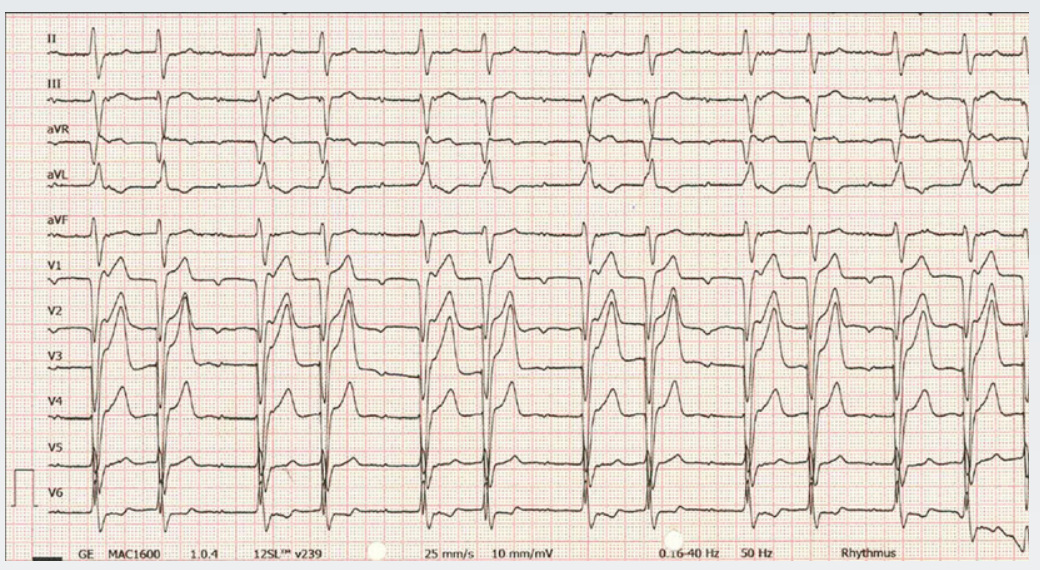

Was meinen Sie?

a) Es besteht Vorhofflattern mit unregelmäßiger Überleitung.

b) Es besteht ein AV-Block $I^{\circ}$ und ein unbestimmter Schenkelblock.

c) Es besteht ein AV-Block $I^{\circ}$ Typ Wenckebach (= Mobitz 1).

Die Lösung dieses Falls sowie weitere spannende 107 EKG-Fälle in unterschiedlichen Schwierigkeitsstufen mit Lösungshinweisen und ausführlichen Kommentaren finden Sie im Intensivkurs-EKG von Herrn PD Dr. Carsten W. Israel, Bielefeld. Verbessern Sie Ihre Routine in der Interpretation von EKG-Aufzeichnungen!

Einfach diesen QR-Code scannen:

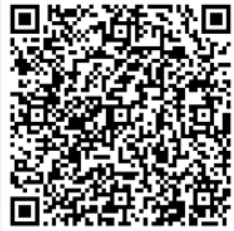

